\title{
Comparitive Study of Magnetic Resonance Cholangiopancreatography with Endoscopic Retrograde Cholangiopancreatography in Biliary And Pancreatic Duct Abnormalities
}

\author{
* Paarthipan Natarajan ${ }^{1}$ *S Sureendhar Mohan ${ }^{2}$,Prem Kumar ${ }^{3}$,Rajalakshmi K \\ ${ }^{4}$,Rajasekhar K.V. ${ }^{5}$.

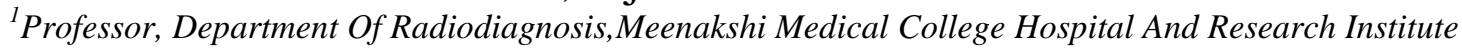 \\ (MMCH \& RI), Kanchipuram \\ ${ }^{2}$ Assistant Professor, Department Of Radiodiagnosis,Meenakshi Medical College Hospital And Research \\ Institute(MMCH \& RI), Kanchipuram \\ ${ }^{3}$ Post Graduate, Department Of Radiodiagnosis, Meenakshi Medical College Hospital And Research \\ Institute(MMCH \& RI), Kanchipuram. \\ ${ }^{4}$ Post Graduate, Department Of Radiodiagnosis, Meenakshi Medical College Hospital And \\ Researchinstitute(MMCH \& RI), Kanchipuram. \\ ${ }^{5}$ Professor And Head, Department Of Radiodiagnosis, Meenakshi Medical College Hospital And Research \\ Institute(MMCH \& RI), Kanchipuram.
}

\begin{abstract}
Aim And Objectives: To recognize the normal appearence of bile duct \& pancreatic duct and its variants by MRCP.To compare the accuracy of MRCP as a diagnostic tool in our institution with ERCP in the diagnosis of bile and pancreatic duct diseases, using specificity, sensitivity, positive and negative predictive values.

Materials And Methods: Source of data :Patients from Departments of General Surgery, General Medicine \& Gastroenterology with features of bile and pancreatic ducts diseases who are referred to the Department of Radiodiagnosis of Meenakshi Medical College and Research Institute. Method of Collection of Data: Number of patients for study - 50. A standard proforma will be used to collect patient related data for the study. The patients will be subjected to MRCP evaluation in 1.5TESLA Maganetom Essenza Siemens MRI machine and ERCP evaluation in side view scope Olympus and C-arm Philps BV Vectra. Study design: Retrospective study . Study period: January2015to october 2016 Consent : Informed consent obtained from all patients.

Conclusion: MRCP has highest sensitivity, specificity, and diagnostic accuracy than ERCP in diagnosing obstruction due to pancreaticobiliary disorders. MRCP is able to determine accurately more cases than ERCP in both cause and extent of obstruction. Anatomy of biliary tree is well delineated by MRCP. Bileducts proximal as well as distal to the level of obstruction is made out better by MRCP. Due to invasiveness and contrast media induced allergic reactions, diagnostic usage of ERCP is limited. ERCP is mainly reserved for patients who required intervention in treating biliary obstruction. From this we can conclude that MRCP is more sensitive and specific in diagnosing pancreaticobiliary disorders than ERCP. ERCP is mainly used for therapeutic purposes.
\end{abstract}

\section{Introduction}

Magnetic resonance cholangiopancreatography (MRCP) is now a relatively new technique which has proved a robust and for noninvasively images the biliary passage and pancreatic duct. Sequences used in MRCP are performed with moderately and heavily T2 - weighted sequences which readily depicts the relatively static fluid present within the $\mathrm{p}$ ancreatic duct and biliary duct. MRCP shows high accuracy for diagnosing anatomic variants of both the intrahepatic and extrahepatic bile ducts and cystic duct. At present MRCP to provides a detailed map of anatomic variations in preoperative patients at increased risk of bile duct injury including patients with acute cholecystitis, obesity, patients scheduled to undergo complicated biliary reconstruction or prior abdominal surgery. This technique is a useful alternative to more invasive procedures like endoscopic retrograde cholangiopancreatography (ERCP), which should be used only in cases where intervention is needed. Single-shot fast spin-echo is a newer and more rapid MRCP sequence that can be performed in a single breath hold, thereby significantly reducing motion artifacts and increasing image quality. The coronal plane is used to provide a cholangiographic display. The axial plane is used to evaluate the pancreatic duct and distal common bile duct. Endoscopic retrograde cholangiopancreatography (ERCP), which was introduced in 1970s, was 
initially designed for diagnostic imaging of the biliary tree. Therapeutic biliary applications for ERCP developed soon after its initial introduction, \& pancreatic applications soon followed. ERCP is performed using a side viewing duodenoscope, which allows to view the medial wall of the duodenum, including an en face view of the ampulla.

An instrument channel in the duodenoscope enables cannulation of the ampulla of Vater under direct visualization, and injection of contrast into the bile duct and pancreatic duct to obtain diagnostic images. The clinical applications of MRCP are numerous and include the diagnosis of common bile duct stones; malignancies of the pancreaticobiliary tract; con genital anomalies such as choledochal cysts, aberrant bile ducts, and pancreas divisum; primary sclerosing cholangitis (PSC); acute and chronic pancreatitis; and gallbladder disease such as stones and carcinoma.

\section{Causes Of Biliary Obstruction}

Based on Anatomical location: Hilar, low/midduct andeither. It is divided into benign and malignant.

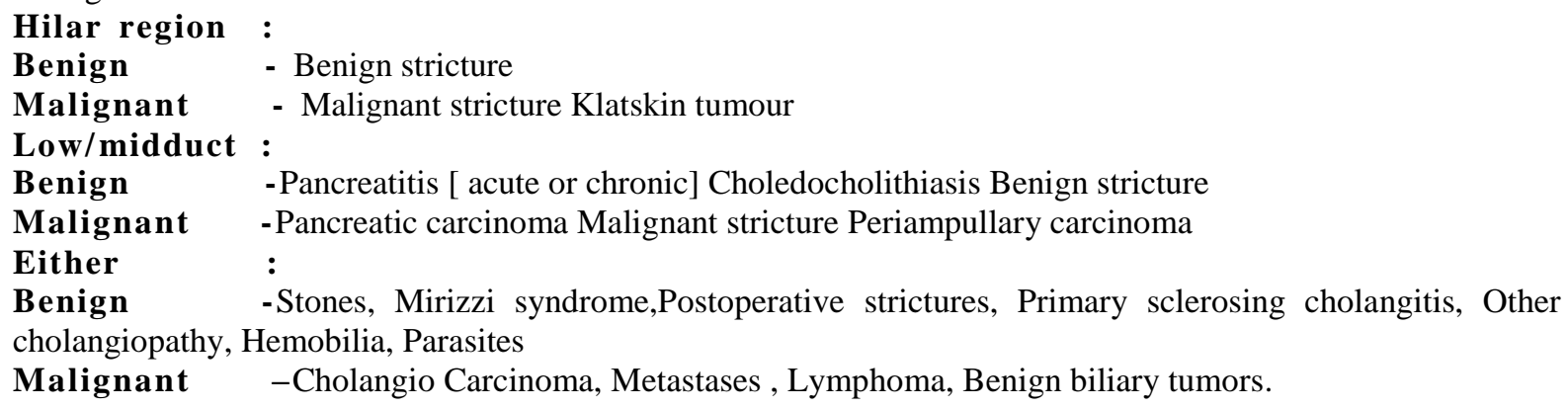

\section{Aim And Objectives}

1. To recognize the normal appearance of bile duct \& pancreatic duct and its variants by MRCP.

2. To compare the accuracy of MRCP as a diagnostic tool in our institution with ERCP in the diagnosis of bile and pancreatic duct diseases, using specificity, sensitivity, positive and negative predictive values.

\section{Materials And Methods}

Source of Data : Patients from Departments of General Surgery , General Medicine\& Gastroenterology with features of bile and pancreatic ducts disease who are referred to the Department of Radiodiagnosis of Meenakshi Medical College and Research Institute from January 2015 to October 2016

\section{Method of collection of data:}

Number of patients for study - 50. A standard proforma will be used to collect patient related data for the study. The patients were subjected to MRCP evaluation in 1.5TESLA Maganetom Essenza SIEMENS MRI Machine and ERCP evaluation was performed using side view scope Olympus And C- Arm Philps BV Vectra.

Study design : Retrospective study

Study period : January2015 to October 2016

Place : Department of Radiology, Meenakshi Medical College \& Research Instutite, Enathur, kanchipuram

Collaborating Unit : Department of Medical Gastroenterology,Meenakshi Medical College \&Research Instutite, Enathur, kanchipuram.

Consent : Consent Informed consent obtained from all patients.

\section{Inclusion Criteria}

- Patients referred for MRCP to the department of radiodiagnosis for evaluation of bile and pancreatic duct abnormalities

- Congenital anomalies.

- Patients with history of obstructive jaundice, pain abdomen \& cholangitis.

- The results were correlated with ERCP.

- Where ever the histopathology is needed

\section{Exclusion Criteria}

- Poorly adequate images due to inadequate patient breath holding and motion artifacts

- Patients with claustrophobia,

- Patients with cardiac pacemakers, 
- Patients with metallic orthopedic implants \& intraorbital metallic foreign bodies,

- Hemodynamically unstable patients.

Technique:

MRCP is performed with heavily T2 -weighted sequences by using fast spin-echo software( ŭsing respiratory gating) and both a thick collimation (single section)and thin collimation(multisection) technique with a torso phase- array coil.The coronal plane is used to evaluatre the pancreatic duct and distal common bile duct. In addition, three-dimensional reconstruction by using a maximum intensity projection (MIP) algorythm on the thin- collimation source image is performed.

\section{Result And Analysis}

The data were collected from a sample of 50 patients. this part deals with the analysis and interpretation of data collected.The study subjects consisted of 28 male and 22 female patients, between the age of 24 to 60 years (with mean age of $43.56 \pm 8.49$ years).

\section{The Distribution Of Demographical Characteristics Of Study Sample}

Table-1 : Gender Distribution

\begin{tabular}{|l|l|l|}
\hline Gender & No of patients & $\%$ \\
\hline Male & 28 & 56 \\
\hline Female & 22 & 44 \\
\hline Total & 50 & 100 \\
\hline
\end{tabular}

From the above table- 1, a total sample of 50 was used for analysis. Males comprised 28 (56 \%) and female $22(44 \%)$ of the total 50 cases. Same subjects were included both MRCP and ERCP study. Majority of them were male

Table-2 : Age distribution

\begin{tabular}{|c|c|c|c|c|c|c|}
\hline \multirow{2}{*}{$\begin{array}{c}\text { Age Group } \\
\text { (in Years) }\end{array}$} & \multicolumn{2}{|c|}{ Male } & \multicolumn{2}{c|}{ Female } & \multicolumn{2}{c|}{ Total } \\
\cline { 2 - 7 } & $\mathbf{N}$ & $\%$ & $\mathbf{N}$ & $\%$ & $\mathbf{N}$ & $\%$ \\
\hline $20-30$ & 2 & 7.15 & 3 & 13.64 & 5 & 10.00 \\
\hline $31-40$ & 10 & 35.71 & 5 & 22.73 & 15 & 30.00 \\
\hline $41-50$ & 8 & 28.57 & 10 & 45.45 & 18 & 36.00 \\
\hline $51-60$ & 8 & 28.57 & 4 & 18.18 & 12 & 24.00 \\
\hline Total & 28 & 100 & 22 & 100 & 50 & 100 \\
\hline
\end{tabular}

Table -2 reveals that distribution of the age group. $18(36 \%)$ are in the age group of $41-50$ years, Irrespective of their sex. Further i t reveals that $15(30 \%)$ of the patients belong to the age group of $31-40$ years, $12(24 \%)$ of the patients belongs to the 51- 60 years of the age group and $5(10 \%)$ are in the age group of 20 - 30 years.

Table-3 : Clinical Presentation

\begin{tabular}{|c|c|c|c|c|c|c|}
\hline \multirow{2}{*}{$\begin{array}{c}\text { Clinical } \\
\text { presentation }\end{array}$} & \multicolumn{2}{|c|}{ Male } & \multicolumn{2}{|c|}{ Female } & \multicolumn{2}{|c|}{ Total } \\
\hline & $\mathbf{N}$ & 96 & $\mathbf{N}$ & 96 & $\mathbf{N}$ & 96 \\
\hline Obstructive Jaundice & 11 & 39.29 & 11 & 50.00 & 22 & 44.00 \\
\hline Pain Abdomen & 10 & 35.71 & 11 & 50.00 & 21 & 42.00 \\
\hline $\begin{array}{c}\text { Clinical features of } \\
\text { Cholangitis }\end{array}$ & 7 & 25.00 & 0 & 0 & 7 & 14.00 \\
\hline \multirow[t]{2}{*}{ Total } & 28 & 100 & 22 & 100 & 50 & 100 \\
\hline & \multicolumn{4}{|c|}{$\begin{array}{c}\text { Chi Square }=6.42 \mathrm{df}=2 \\
p=0.04 \text { Significant }\end{array}$} & & \\
\hline
\end{tabular}

Table-3 shows that, 22 (44\%) had the complaints of the obstructive Jaundice, 21 (42\%) had Pain Abdomen and a small $7(14 \%)$ had Cholangitis. It is clear that the male and female patients differ with 
regards to their complaints ( $\mathrm{X} 2=6.42, \mathrm{df}=2, \mathrm{P}<0.04$ ).

Graph 1:

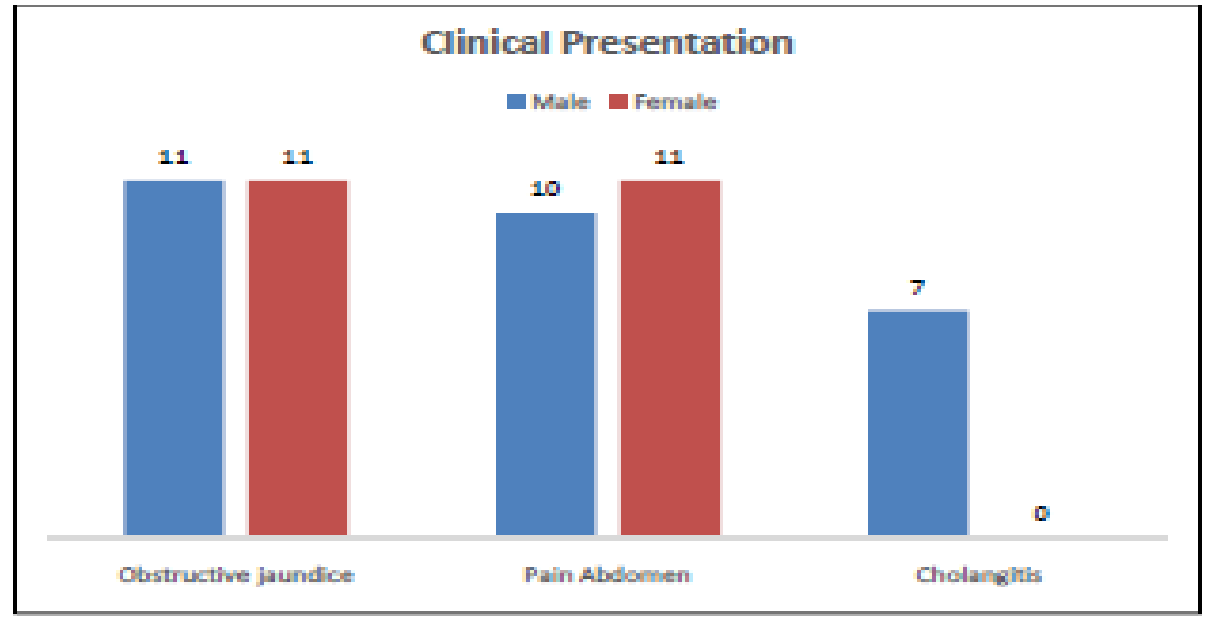

Table-4 : MRCP based on Cause of obstruction

\begin{tabular}{|c|c|c|c|c|c|c|c|}
\hline \multirow{2}{*}{ S.No } & \multirow{2}{*}{ Cause of Obstruction } & \multicolumn{2}{|c|}{ Male } & \multicolumn{2}{|c|}{ Female } & \multicolumn{2}{|c|}{ Total } \\
\hline & & No. & 96 & No. & 90 & No & $9 \%$ \\
\hline 1 & $\begin{array}{l}\text { BS-PC-Benign Stricture - Post } \\
\text { Cholecystectomy }\end{array}$ & 2 & 7.10 & 5 & 22.70 & 7 & 14.00 \\
\hline 2 & C-CA-Cholangio Carcinoma & 0 & 0 & 1 & 4.50 & 1 & 2.00 \\
\hline 3 & CC-CBD Calculus & 3 & 10.70 & 1 & 4.50 & 4 & 8.00 \\
\hline 4 & CH-P-Chronic Pancreatitis & 3 & 10.70 & 0 & 0 & 3 & 6.00 \\
\hline 5 & Ch-Cy-Choledochal Cyst & 2 & 7.10 & 3 & 13.60 & 5 & 10.00 \\
\hline 6 & $\begin{array}{c}\text { P-divisum } \\
\text { Pancreatic divisum }\end{array}$ & 4 & 14.30 & 0 & 0 & 4 & 8.00 \\
\hline 7 & GC+CC-GB Calculus +CBD Calculus & 3 & 13.6 & 3 & 13.6 & 6 & 12.00 \\
\hline 8 & MI-SY-Mirizzi syndrome & 2 & 7.10 & 0 & 0 & 2 & 4.00 \\
\hline 9 & $\begin{array}{c}\text { MS-KT-Malignant Stricture - Klatskin } \\
\text { Tumour }\end{array}$ & 1 & 3.60 & 5 & 22.70 & 6 & 12.00 \\
\hline 10 & PA-CA-Pancreatic Carcinoma & 2 & 7.10 & 0 & 0 & 2 & 4.00 \\
\hline 11 & PC-Periampullary carcinoma & 3 & 10.70 & 1 & 4.50 & 4 & 8.00 \\
\hline 12 & PS-CH-Primary Sclerosing Cholangitis & 1 & 3.60 & 1 & 4.50 & 2 & 4.00 \\
\hline 13 & Inconclusive & 2 & 7.10 & 2 & 9.10 & 4 & 8.00 \\
\hline & Total & 28 & 100 & 22 & 100 & 50 & 100 \\
\hline
\end{tabular}

From the above table, Irrespective of of their sex, 7 (14\%) are having Benign Stricture with Post Cholecystectomy, 6 cases(12\%) GB Calculus + CBD Calculus. 6 (12\%) are having Malignant stricture with Klatskin Tumour,5 (10\%) are having Choledochal Cyst, 4(8\%) are having CBD calculus, $4(8 \%)$ are having Periampullary carcinoma, $4(8 \%)$ are having pancreatic divisum, $3(6 \%)$ are having Chronic Pancreatitis, $2(4 \%)$ are havi ng Mirizzi syndrome, $2(4 \%)$ are having Primary Sclerosing Cholangitis, 2 (4\%) are having pancreatic carcinoma, $1(2 \%)$ is having Cholangio Carcinoma and $4(8 \%)$ are found inconclusive.

Table-5 : Mrcp - Type Of Causes

\begin{tabular}{|c|c|c|}
\hline Type of causes & No. & 96 \\
\hline CALCULUS & 10 & 20.00 \\
\hline STRICTURE & 15 & 30.00 \\
\hline TUMORS & 7 & 14.00 \\
\hline CYST & 5 & 10.00 \\
\hline EXTRINSIC CAUSES & 9 & 18.00 \\
\hline Inconclusive & 4 & 8.00 \\
\hline Total & 50 & 100 \\
\hline
\end{tabular}


Table reveals that type of causes , 15( $30 \%)$ was found to be Stricture, Calculus found in 10 (20\%), 7 (14\%) was found to be Tumors, 5 (10\%) were found to be Cysts and Extrinsic Causes are having 9(18\%) and 4(8\%) are found to be Inconclusive

Table 6: ERCP based on Cause of obstruction

\begin{tabular}{|c|c|c|c|c|c|c|c|}
\hline \multirow{2}{*}{$\begin{array}{l}\text { S. } \\
\text { No. }\end{array}$} & \multirow{2}{*}{ Cause of Obstruction } & \multicolumn{2}{|c|}{ Male } & \multicolumn{2}{|c|}{ Female } & \multicolumn{2}{|c|}{ Total } \\
\hline & & No. & $\%$ & No. & $\%$ & $\mathbf{N}$ & 96 \\
\hline 1 & BS-PC-Benign Stricture- Post Cholecystectomy & 2 & 7.15 & 3 & 13.60 & 5 & 10.00 \\
\hline 2 & C-CA-Cholangio Carcinoma & - & - & 1 & 4.50 & 1 & 2.00 \\
\hline 3 & CC-CBD Calculus & 3 & 10.70 & 2 & 9.10 & 5 & 10.00 \\
\hline 4 & CH-P-Chronic Pancreatitis & 3 & 10.70 & - & - & 3 & 6.00 \\
\hline 5 & Ch-Cy-Choledochal Cyst & 2 & 7.15 & 3 & 13.60 & 5 & 10.00 \\
\hline 6 & -divisum - Pancreatic divisum & 4 & 14.30 & - & $\cdot$ & 4 & 8.00 \\
\hline 7 & GC-CC-GB Calculus + CBD Calculus & 3 & 10.70 & 3 & 13.60 & 6 & 12.00 \\
\hline 8 & MI-SY-Mirizzi syndrome & 2 & 7.15 & - & - & 2 & 4.00 \\
\hline 9 & MS-KT-Malignant Stricture - Klatskin Tumour & 1 & 3.60 & 3 & 13.60 & 4 & 8.00 \\
\hline 10 & A-CA - Pancreatic Carcinoma & 2 & 7.15 & - & - & 2 & 4.00 \\
\hline 11 & PC - Periampullary carcinoma & 3 & 3.60 & 1 & 4.50 & 4 & 8.00 \\
\hline 12 & SS-CH -Primary Sclerosing Cholangitis & - & - & 1 & 4.50 & 1 & 2.00 \\
\hline \begin{tabular}{|l|}
13 \\
\end{tabular} & Inconclusive & 3 & 10.70 & 5 & 22.75 & 8 & 16.00 \\
\hline & Total & 28 & 100.00 & 22 & 100.00 & 50 & 100.00 \\
\hline
\end{tabular}

From the above table, Irrespective of their sex 6 cases(12\%) GB Calculus + CBD Calculus, 5 cases $(10 \%)$ are having Benign Stricture due to Post Cholecystectomy sequelae, 5 cases (10 \%) are having Choledochal Cyst, 5 cases (10\%) are having CBD calculu s, 4 cases (8\%) are having Malignant stricture due to Klatskin Tumour, $4(8 \%)$ cases Periampullary carcinoma,4 (8\%) pancreatic divisum, 3 cases $(6 \%)$ Chronic Pancreatitis, 2 cases (4\%) Mirizzi syndrome, 2 cases (4\%) Pancre atic Carcinoma, 1 case $(2 \%)$ Primary Sclerosing Cholangitis and $8(16 \%)$ cases are inconclusive.

Table-7 : ERCP in type of Cause of obstruction

\begin{tabular}{|l|c|c|}
\hline \multicolumn{1}{|c|}{ Type of causes } & No. & $\%$ \\
\hline CALCULUS & 11 & 22.00 \\
\hline STRICTURE & 10 & 20.00 \\
\hline TUMORS & 7 & 14.00 \\
\hline CYST & 5 & 10.00 \\
\hline EXTRINSIC CAUSES & 9 & 18.00 \\
\hline Inconclusive Total & 8 & 16.00 \\
\hline \multicolumn{2}{c|}{50} & 100 \\
\hline
\end{tabular}

The above table reveals that ERCP was able to detect Calculus in 11 (22\%) cases, Stricture in 10 $(20 \%)$ cases, Tumors in $7(14 \%)$ cases, Cyst in $5(10 \%)$ cases \& Extrinsic Causes in $5(10 \%)$ cases and 8 $(16 \%)$ are found inconclusive. 
Table-8 : Comparison of ERCP vs MRCP in Pathological findings

\begin{tabular}{|c|l|c|c|c|}
\hline S.No & \multicolumn{1}{|c|}{ PATHOLOGICAL FINDINGS } & $\begin{array}{c}\text { Total } \\
\text { No. case }\end{array}$ & MRCP & ERCP \\
\hline 1 & $\begin{array}{l}\text { BS-PC- Benign Stricture - Post } \\
\text { Cholecystectomy }\end{array}$ & 7 & 7 & 5 \\
\hline 2 & C-CA-Cholangio Carcinoma & 1 & 1 & 1 \\
\hline 3 & CC-CBD Calculus & 5 & 4 & 5 \\
\hline 4 & CH-P - Chronic Pancreatitis & 3 & 3 & 3 \\
\hline 5 & Ch-Cy- Choledochal Cyst & 5 & 5 & 5 \\
\hline 6 & P-divisum - Pancreatic divisum & 4 & 4 & 4 \\
\hline 7 & GC+CC-GB Calculus + CBD Calculus & 6 & 6 & 6 \\
\hline 8 & MI-SY- Mirizzi syndrome & 2 & 2 & 2 \\
\hline 9 & $\begin{array}{l}\text { MS-KT- Malignant Stricture - Klatskin } \\
\text { Tumour }\end{array}$ & 6 & 6 & 4 \\
\hline 10 & PA-CA- Pancreatic Carcinoma & 2 & 2 & 2 \\
\hline 11 & PC- Periampullary carcinoma & 4 & 4 & 4 \\
\hline 12 & PS-CH-Primary Sclerosing Cholangitis & 2 & 2 & 1 \\
\hline 13 & Inconclusive & 3 & 4 & 8 \\
\hline & $\mathbf{5 0}$ & $\mathbf{5 0}$ & $\mathbf{5 0}$ \\
\hline
\end{tabular}

Both MRCP and ERCP failed to detect 3(6\%) cases and found to be inconclusive. MRCP failed to detect 1 (2\%) CBD calculus, which was found in ERCP. In contrast to MRCP, ERCP failed detect 8 cases are $2(4 \%)$ in benign stricture - post cholecystectomy, 2(4\%)malig nant stricture -Klatskin tumour, 1(2\%) case primary sclerosing cholangitis and $3(6 \%)$ case s are found inconclusive.

Table-9 : Sensitivity of MRCP

\begin{tabular}{|c|c|c|c|}
\hline MRCP & Disease Present & Disease absent & Total \\
\hline $\begin{array}{c}\text { Test Positive } \\
\text { (Determined) }\end{array}$ & 46 & 0 & 46 \\
\hline $\begin{array}{c}\text { Test Negative } \\
\text { (Not Determined) }\end{array}$ & 1 & 3 & 4 \\
\hline TOTAL & 47 & 3 & 50 \\
\hline
\end{tabular}

Sensitivity $=97.87 \%$

Specificity $=100.00 \%$

Positive predictive value $(\mathrm{PPV})=100.00 \%$

Negative predictive value(NPV) $=75.00 \%$

False positive Rate $(\mathrm{FNR})=0.00 \%$

False Negative Rate(FNR) $=2.12 \%$

Accuracy $($ ACC $)=98 \%$

MRCP is detecting $97.87 \%$ of positive cases \& $75.0 \%$ negative cases correctly . 
Graph 2:

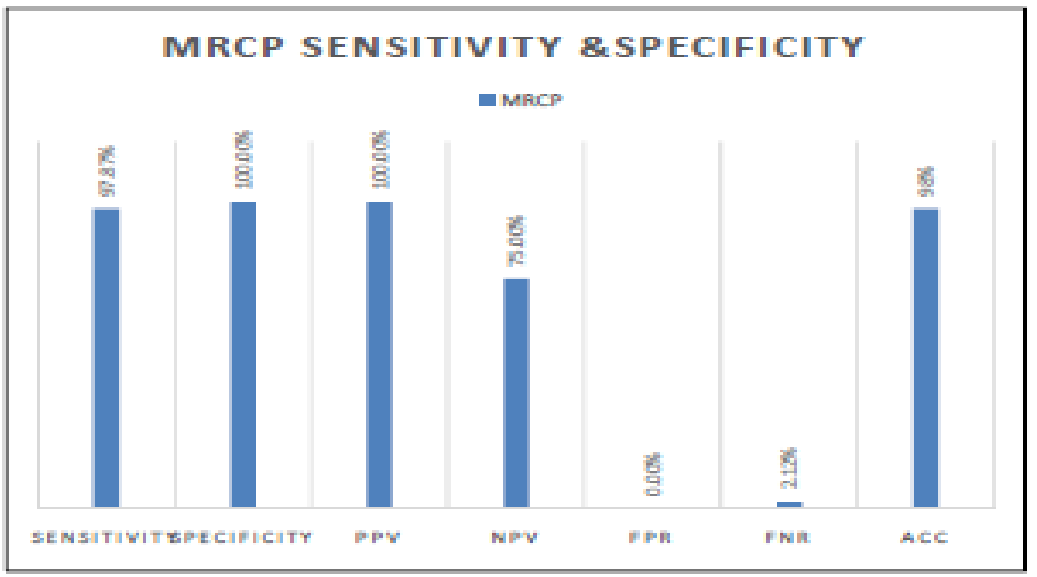

Table-10: Sensitivity of ERCP

\begin{tabular}{|l|c|c|c|}
\hline \multicolumn{1}{|c|}{ ERCP } & $\begin{array}{c}\text { Disease } \\
\text { Present }\end{array}$ & Disease Absent & Total \\
\hline $\begin{array}{l}\text { Test positive } \\
\text { (Determined) }\end{array}$ & 42 & 0 & 42 \\
\hline $\begin{array}{l}\text { Test negative(Not } \\
\text { Determined) }\end{array}$ & 5 & 3 & 8 \\
\hline TOTAL & 47 & 3 & 50 \\
\hline
\end{tabular}

Sensitivity $=89.36 \%$, Specificity $=100.00 \%$

Positive Predictive Value ( PPV) $=100.00 \%$

Negative Predictive Value (NPV) $=37.50 \%$

False Positive Rate $($ FPR $)=0.00 \%$

False Negative Rate (FNR) $\quad=\quad 10.63 \%$

Accuracy (ACC) $(\mathrm{ACC})=90.00 \%$

ERCP is detecting $89.36 \%$ of positive cases and $37.50 \%$ negative cases correctly.

Graph 3:

ERCP SENSITIVITY AND SPECIFICITY

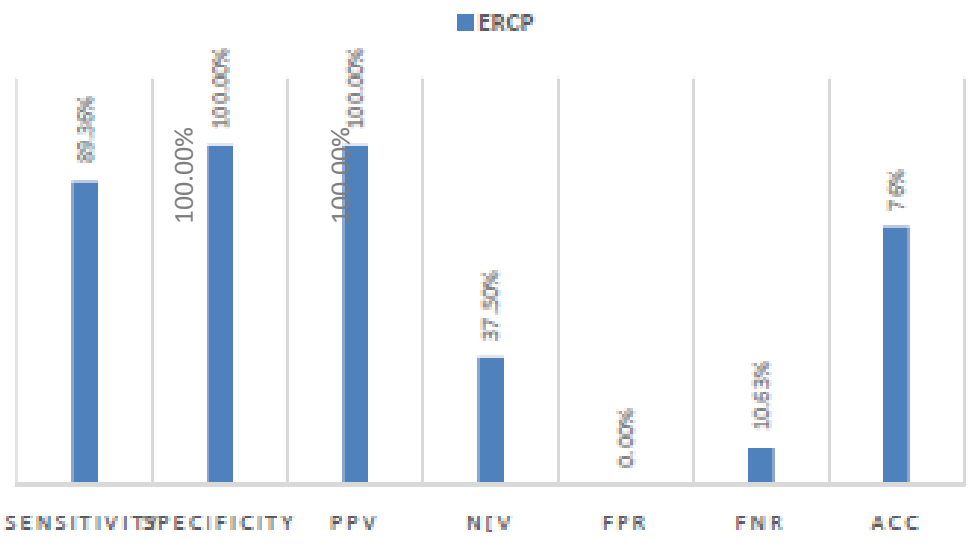


Comparitive Study Of Magnetic Resonance Cholangiopancreatography With... .

Table-11 Comparison of specificity and sensitivity in MRCP \& ERCP.

\begin{tabular}{|l|c|c|}
\hline & MRCP & ERCP \\
\hline Sensitivity & $97.87 \%$ & $89.93 \%$ \\
\hline Specificity & $100.00 \%$ & $100.00 \%$ \\
\hline Positive Predictive Value ( PPV) & $100.00 \%$ & $100.00 \%$ \\
\hline Negative Predictive Value (NPV) & $75.00 \%$ & $37.50 \%$ \\
\hline False Positive Rate (FPR) & $0.00 \%$ & $0.00 \%$ \\
\hline False Negative Rate (FNR) & $2.12 \%$ & $10.63 \%$ \\
\hline Accuracy (ACC) & $98.00 \%$ & $90.00 \%$ \\
\hline
\end{tabular}

While comparing MRCP and ERCP all the values were higher then the ERCP values expect False Negative Rate (FNR). This Shows that MRCP is clearly showing superior to ERCP in mapping out the extent of obstruction.

\section{Discussion}

The aim of our study was to compare the accuracy of MRCP with invasive ERCP in the diagnosis of bile and pancreatic abnormalities using specificity, sensitivity, positive and negative predictive values. Our study was conducted in 50 patients ( 28 males and 22 females) whoever referred to MRCP with clinical features pertaining to bile and pancreatic duct abnormalities and the same number of patients were underwent ERCP within $24-72$ hrs. In a study by D Hurter et al(2008) females are higher in the study but slightly male preponderance seen in our study.

A sizeable percentage (36\%) of the patients belongs to the age group $41-50$ years. In our study the mean age group comes down to a lower level in comparison with a study by D Hurter et al(2008). Obstructive Jaundice is the commonest feature comprising $44 \%$ followed by $42 \%$ with Pain Abdomen and $14 \%$ with Cholangitis. Our study well correlates with M Park et al(2004) where obstructive jaundice is seen in almost all the patients. There is no significant difference between male and female among the clinical features. MRCP was able to detect Cause and type of obstruction such as Stricture in $30 \%$ cases, Calculus in $20 \%$ cases, Tumours in $14 \%$ cases, $18 \%$ in Extrinsic cases, $10 \%$ in Cyst cases and 8\% cases are inconclusive. Stricture is the commonest cause of obstructive jaundice in cases diagnosed with MRCP. ERCP was able to detect Cause and type of obstruction such as calculus $22 \%$, Stricture in $20 \%$ cases, Tumours in $14 \%$ cases, Extrinsic causes in $18 \%$ cases \& cyst in $10 \%$ of cases and $8(16 \%)$ cases are inconclusive.

Stricture and calculus are the commonest cause of obstructive jaundice in cases diagnosed with ERCP. MRCP was compared with ERCP based on Cause of Obstruction. MRCP diagnosed Calculus in 10 $(20 \%)$ cases and ERCP diagnosed $11(22 \%)$ cases. $1(2 \%)$ case was missed by MRCP and detected by ERCP due to very small size $3 \mathrm{~mm}$. In cases with Stricture(benign and malignant) MRCP diagnosed 15 (30\%) cases and ERCP diagnosed only 10(20 \%) cases, ERCP has failed to determine 5 (10 \%) cases due to tight nonnegotiable strciture. MRCP and ERCP were equally sensitive in cases with tumors 7 (14\%) cases, cysts 5 $(10 \%)$ cases and extrinsic causes $9(14 \%)$ cases, no cases were missed out. In $3(6 \%)$ cases both MRCP and ERCP had failed to detect cause of obstruction. The results are Inconclusive. Pancreatic divisum 4 (8\%) was diagnosed by both MRCP \& ERCP. Two cases of malignant stricture(Klatskin tumour) - missed due to both short segment stricture was not diagnosed by ERCP \& diagnosed by MRCP. MRCP was able to diagnose 46( 92 $\%$ ) cases against 1 ( $2 \%$ ) case $\mathrm{w}$ as missed to diagnose the extent of obstruction. In ERCP $42(84 \%)$ cases were diagnosed but $8(16 \%)$ cases were missed to determine the extent of obstruction. In our study MRCP was able to diagnose more cases than ERCP and also the extent of obstruction. In our study MRCP has $97.87 \%$ sensitivity, $100.00 \%$ Spe cificity \& $98 \%$ accuracy rate. ERCP has $89.33 \%$ sensitivity, $100.00 \%$ Specificity and accuracy in $90 \%$ in determining the cause and extent of obstruction.Our study correlates well with D Hurter et al(2008) and Guiband L et al(1995) where they able to get similar results. In our study MRCP's Sensitivity level $(97.87 \%)$ is more than ERCP ( $89.33 \%)$. MRCP determine accurately more cases than ERCP in both cause and extent of obstruction. A M Halefoglu et al(2007) also stated that MRCP is a noninvasive tool and has a comparable accuracy to ERCP which is more invasive and difficult procedure.

From that we can say that MRCP is superior to ERCP in mapping out the extent of obstruction. This is use full in planning further management of the disease. Thus MRCP may replace ERCP for diagnostic purposes. ERCP may then be reserved for patients who required intervention in treating biliary obstruction. MRCP is a comparable diagnostic investigation on par with ERCP for diagnosing biliary abnormalities. Results were particularly fav ourable for choledocholethiasis, stricture, malignancy and choledochal cyst. Less favourable for pancreatitis. The use of MRCP reduces the need for diagnostic ERCP which is associated with 
significant morbidity and mortality.

Magnetic Resonance Cholangio Pancratography is superior modality when compared with Endoscopic

Retrograde Cholangio Pancretography mainly because it is

1. Non invasive procedure

2 No radiation required

3. Anaesthesia is not required

4. Can be performed in patients when endoscope access is unavailable or unsuccessful.

5. Demonstrates anatomic variants preoperatively.

6. It can give a detailed map of biliary tree allowing visualization of ducts, proximal as well as distal to the level of obstruction

7. Can show the extent of lesion more accurately than ERCP.

\section{The Real Benefits Of ERCP Include:}

1. Ability to offer therapeutic intervention at the time of the procedure;

2 Manometry can be performed;

3 The ampulla of Vater can be directly visualized;

4 The radiographic images obtained with ERCP have a higher spatial resolution.

5 Able to get $t$ issue sample for histopathological evaluation.

\section{Pit Falls Of Mrcp}

Pseudo filling defects are usually due to stones, air,tumors, hemorrhage, or sludge. Infrequent causes of filling defects include susceptibility artifact from adjacent clips, metallic bile duct stents, folds or flow voids.

Pseudodilatations can occur if the cystic duct crosses the common bile duct or courses parallel to it or if extraductal fluid -filled structures (eg, intestine, pseudocysts, gallbladder) are volume averaged with the ducts.Nonvisualization of the intrahepatic bile ducts may be a normal finding due to nondistention; however, nonvisualization of the extrahepatic bile ducts may be due to obscuration by extraductal fluid - filled structures (eg, intestine, pseudocysts, gallbladder), intravenous administration of manganese, or pneumobilia.

\section{Pit Falls Of Ercp}

Pancreatic duct in the head of the pancreas may take a steep downward course to the papilla, paralleling the common bile duct. In this circumstance a partially filled pancreatic duct can be confused with the bile duct on fluoroscopy. The main pancreatic duct is occasionally narrowed at its junction with the accessory duct; it is important not to misinterpret this normal variant asa duct stricture. ERCP artifacts may be caused by endoscopic equipment (e. g., pressure from the cannula or endoscope distorting the distal bile duct), contrast material injected outside the ductal systems, nonpancreaticobiliary calcifications, bowel gas overlying the area of interest, incomplete filling of ducts, and unintentional injection of air. Pancreatic duct artifacts are commonly caused by inadvertent contrast injection in an inappropriate location. Unintentional cannulation of a pancreatic duct side branch followed by contrast injection can lead to branch duct rupture and contrast extravasation Pancreatic duct underfilling is a frequent cause of erroneous diagnosis of ductal stricture or obstruction, usually when the tail has not been opacified.

Injection of contrast material that is too dense, particularly into a dilated duct, may obscure small calculi. Dilute contrast material is preferable when calculi are suspected, especially in a dilated common duct.A contracted biliary sphincter may mimic a stricture or calculus of the distal bile duct.Streaming of contrast material in the bile duct refers to contrast material flowing along the dependent wall of a dilated duct rather than completely filling the lumen. This effect causes an illusion of normal caliber when the duct is dilated further contrast injection shows the true size of the duct.

\section{Summary}

Magnetic resonance cholangiopancreatography (MRCP) is relatively a new MR imaging technique that is used for noninvasive work -up of patients with pancreaticobiliary disease. By using heavily T2 - eighted sequences, the signal of static or slow- moving fluid-filled structures such as the bile and pancreatic ducts is greatly increased, resulting in increased duct-to-background contrast. Recent studies have shown that MRCP is comparable with invasive endoscopic retrograde cholangiopancreatography(ERCP) for diagnosis of extrahepatic bile duct and pancreatic duct abnormalities such as choledocholithiasis, benign or malignant obstruction of the bile and pancreatic ducts conge nital anomalies and chronic pancreatitis. MRCP is becoming the initial imaging tool for the biliary system, with ERCP reserved for therapeutic indications. In this study we 
present the spectrum of bile and pancreatic duct abnormalities seen at MRCP with ERCP correlation, including biliary obstruction(choledocholithiasis, benign and malignant strictures); chronic pancreatitis; pancreatic pseudocyst; biliary cystadenoma and cystadenocarcinoma; postsurgical biliary tract alterations; and congenital anomalies with present technique of MRCP, the MRCP appearance of the normal bile ducts and normal pancreatic duct, \& pitfalls \& artifacts of MRCP.

In Our study majority of the patients belongs to the age group 41 - 50 years. Obstructive Jaundice $(44 \%)$ is the commonest clinical feature followed by Pain Abdomen(42\%) and Cholangitis(14\%) .Sensitivity of MRCP was very high and the cause of obstruction was diagnosed in most of the cases except a small distal CBD calculus which was diagnosed by ERCP.In our study, Stricture and calculus are the commonest cause of obstructive jaundice.MRCP and ERCP were equally sensitive in cases with tumors $7(14 \%)$ cases, cysts $5(10 \%)$ cases and extrinsic causes $9(14 \%)$ cases, no cases were missed out.In $3(6 \%)$ cases both MRCP and ERCP had failed to d etect cause of obstruction. The results are Inconclusive. They had medical causes of abdominal pain.In our study MRCP was able to diagnose more cases than ERCP and also the extent of obstruction.In our study MRCP has $97.87 \%$ sensitivity, $100.00 \%$ Specificity \& 98\% accuracy rate. ERCP has $89.33 \%$ sensitivity, 100. $00 \%$ Specificity and accuracy in $90 \%$ in determining the cause and extent of obstruction.In our study MRCP' s Sensitivity level (97.87 \%) is more than ERCP (89.33 \%). MRCP determine accurately more cases than ERCP in both cause \& extent of obstruction.From that we can say that MRCP is superior to ERCP in mapping out the extent of obstruction. This is use full in planning further management of the disease. Thus MRCP may replace ERCP for diagnostic purposes. ERCP may then be reserved for patients who required intervention in treating biliary obstruction. MRCP is a comparable diagnostic investigation on par with ERCP for diagnosing biliary abnormalities. Results were particularly favourable for choledocholethiasis, stricture, malignancy and choledochal cyst. The use of MRCP reduces the need for diagnostic ERCP which is associated with significant morbidity and mortality.

\section{Conclusion}

Anatomy of biliary tree is well delineated by MRCP. MRCP has highest sensitivity, specificity, and diagnostic accuracy than ERCP in diagnosing obstruction due to pancreaticobiliary disorders. MRCP is able to determine accurately more cases than ERCP in both cause and extent of obstruction. Bile ducts proximal as well as distal to the level of obstruction is made out better by MRCP. Due to invasiveness and contrast media induced allergic reactions, diagnostic usage of ERCP is limited. ERCP is mainly reserved for patients who required intervention in treating biliary obstruction. ERCP is mainly used for therapeutic purposes.

From this we can conclude that MRCP is more sensitive and specific in diagnosing pancreaticobiliary disorders than ERCP.

\section{Bibliography}

[1]. Becker CD, Grossholz M, Becker M, Mentha G, dePeyer R, Terrier F. Choledocholithiasis and bileduct stenosis: diagnostic accuracy of MR cholangiopancreatography. Radiology 1997; 205: $523-530$.

[2]. Binmoeller KF, Jue P, Seifert H, et al. Endoscopic pancreatic stent in chronic pancreatitis and a dominant stricture: longterm results. Endoscopy 1995; 27: 638 - 44

[3]. Blasbalg R, Baroni RH, Costa DN, Machado MC. MRI features of groove pancreatitis. AJR Am J Roentgenol 2007; 189 (1):73 80.

[4]. Bret PM, Reinhold C, Taourel P, Guibaud L, tri M, Barkun AN. Pancreasdivisum: evaluation with MRcholangiopancreatography. Radiology 1996;199:99-103.

[5]. Cha SW, Park MS, Kim KW, et al..Choledochal cyst and anomalous pancreaticobiliary ductal union in adults: radiological spectrum and complications. 2008; $32(1): 17-22$.

[6]. David V, Reinhold C, Hochman M, et al. Pitfalls in the interpretation of MR cholangiopancreatography. AJR Am J Roentgenol 1998; 170:1055-1059.

[7]. Dumonceau JM, Deviere J,Le Moine O,et al. Endoscopic pancreatic drainage in chronic pancreatitis associated with ductal stones.Gastrointest Endosc1996;43:547- 55.

[8]. Düșünceli E, Erden A, Erden I. [ Anatomic variations of the bile ducts:

[9]. MRCP findings]. TaniGirisimRadyol. 2004 Dec; 10 (4 ):296 -303.

[10]. Fulcher AS, Turner MA, Capps GW, Zfass AM, Baker KM. Half- Fourier RARE MR cholangiopancreatographyin 300 subjects. Radiology 1998; 207: 21 - 32 .

[11]. Fulcher AS, Turner MA. MR pancreatography: a useful tool for evaluating pancreatic disorders. RadioGraphics 1999; 19: 5 -24.

[12]. Guibaud L,Bret PM,Reinhold C,Atri M,BarkunAN.Bile duct obstruction \& choledocholithiasis:diagnosis with MR cholangiography. Radiology1995;197:109 -115.

[13]. Hall-Craggs MA, Allen CM, Owens CM, et al. MR cholangiography: clinical evaluation in 40 cases. Radiology 1993; 189:423 427 .

[14]. Isoda H, Kataoka M, Maetani Y, Kido A, Umeoka S, Tamai K, Koyama T, Nakamoto Y, Miki Y, Saga T, Togashi K. MRCP imaging at $3.0 \mathrm{~T}$ vs. $1.5 \mathrm{~T}$ : preliminary experience in healthy volunteers. J MagnReson Imaging. 2007 May; 25(5): 1000 - 6. PubMed PMID: 17410562 .

[15]. Khan AS, Paracha SA, Shah Z, Tahir M, Wahab K. Anatomical variations of cystic duct encountered during open cholecystectomy. Khyber Med Univ J 2012; 4 (1): 1922

[16]. Kim JH, Kim M-J, Chung J-J, et al: Differential diagnosis of periampullary carcinomas at MR imaging. Radio Graphics 2002, $22: 1335-1352$. 
[17]. Lee MG, Lee HJ, Kim MH, et al. Extrahepaticbiliary diseases: 3D MR cholangiopancreatographycompared with endoscopic retrograde cholangiopancreatography. Radiology 1997; 202: 663 -669.

[18]. Limanond P, Raman SS, Ghobrial RM, Busuttil RW, Lu DS. The utility of MRCP in preoperative mapping of biliary anatomy in adult -to- adult living related liver transplant donors. 2004 Feb; 19 (2):209 -15

[19]. Liu T, Consorti E, Kawashima A, et al. Patient evaluation and management with selective use of MRCP \& ERCP before laparoscopic cholecystectomy.Ann Surg 2001;234:33 - 40.

[20]. Lopera JE, Soto JA, Munera F. Malignant hilar \& perihilar biliary obstruction:use of MR cholangiography to define the extent of biliary ductal involvement \& plan percutaneous interventions. 2001;220:90-6

[21]. Tzikos F, Kyriakou V, Tsitouridis I. A new variant of Todani type I choledochal cyst. Hippokratia. 2011 Apr;15(2 ):174 -7. PubMed PMID: 22110303; PubMed Central PMCID: PMC3209684.

[22]. MRCP compared to diagnostic ERCP for diagnosis when biliary obstruction is suspected: 2006

[23]. Nadine R. Barsoum a, Ahmed Abdel Samie b, Lamia Adel a, Ramy E. Asaad a et al. Role of MRCP in assessment of biliary variants in living donor 1 iver transplantation (2013) $44,131-136$.

[24]. Reuther G, Kiefer B,Tuchmann A.Cholangiography before biliary surgery: singleshot MR cholangiography versus intravenous cholangiography.1996 Feb; 198 (2 ):561 - 6. Pub Med PMID: 8596866

[25]. Sacher VY, Davis JS, Sleeman D, Casillas J. Role of magnetic resonancecholangiopancreatography in diagnosing choledochal cysts: Case series and review.World J Radiol. 2013 Aug 28;5 (8 ):304 -12

[26]. Sica GT, Miller FH, Rodriguez G, et al.2002.

[27]. Smits ME, Rauws EA, Tytgat GN, et al. Endoscopic treatment of pancreatic stones in patients with chronic pancreatitis. Gastrointest Endosc 1996;43:556 - 60 .

[28]. Soto JA, Yucel EK, Barish MA, Chuttani R, Ferrucci JT. MR cholangiopancreatography after unsuccessful or incomplete ERCP. Radiology. 1996 Apr;199 (1 ):91 - 8. PubMed PMID: 8633178.

[29]. Taourel P, Bret PM, Reinhold C, et al: Anatomic variants of the biliary tree: diagnosis with MR cholangiopancreatography.199:521 $-527,1996$

[30]. Thomas H, Marriott P, Portmann B, Heaton N, Rela M. Cystic dystrophy in heterotopic pancreas: a rare indication for pancreaticoduodenectomy. Hepatobiliary Pancreat Dis Int 2009; 8(2):215-217.

[31]. UenoE,Takada Y, Yoshida I, TodaJ,sugiuraT,Toki F. pancreatic diseases: evaluation with MR cholangiopancreatography. pancreas 1998: 16;418- 426

[32]. Yu J, Turner MA, Fulcher AS, Halvorsen RA. Congenital anomalies and normal variants of the pancreaticobiliary tract a nd the pancreas in adults. II. Pancreatic duct and pancreas. AJR Am J Roentgenol 2006; 187 (6 ): 1544 -1553.

Figure 1: Normal Anatomy of MRCP

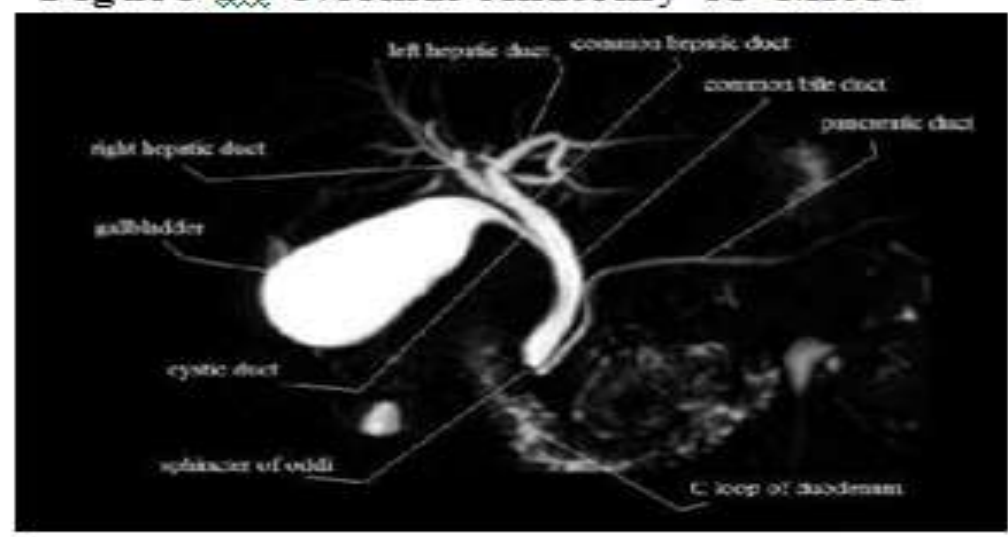

Figure 2: Normal anatomy of ERCP.

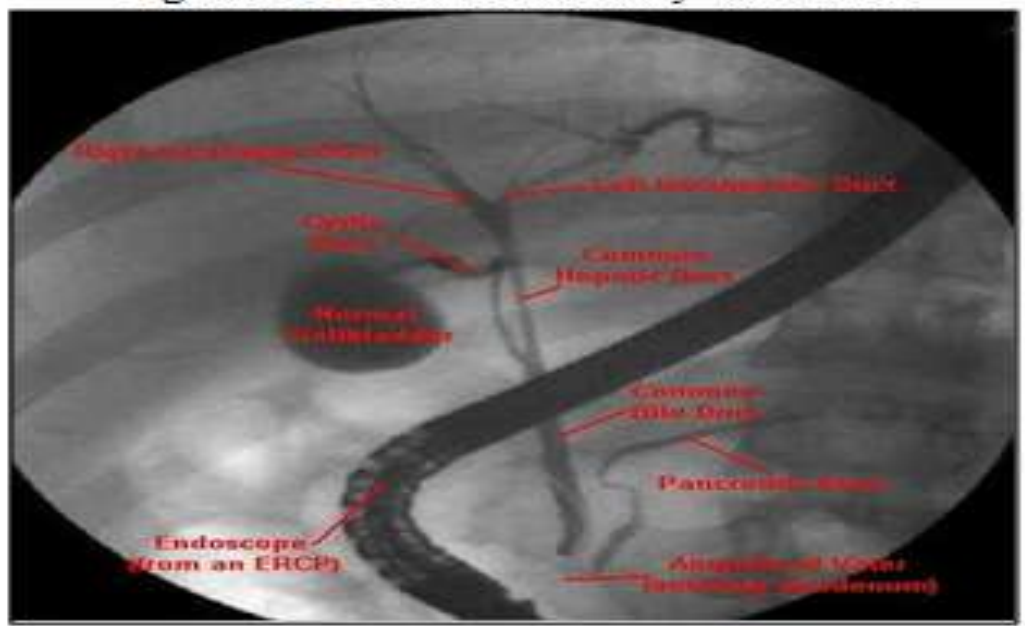


Figure 3: Early development of the ventral (solid arrow) and dorsal buds (dashed arrow) prior to rotation.

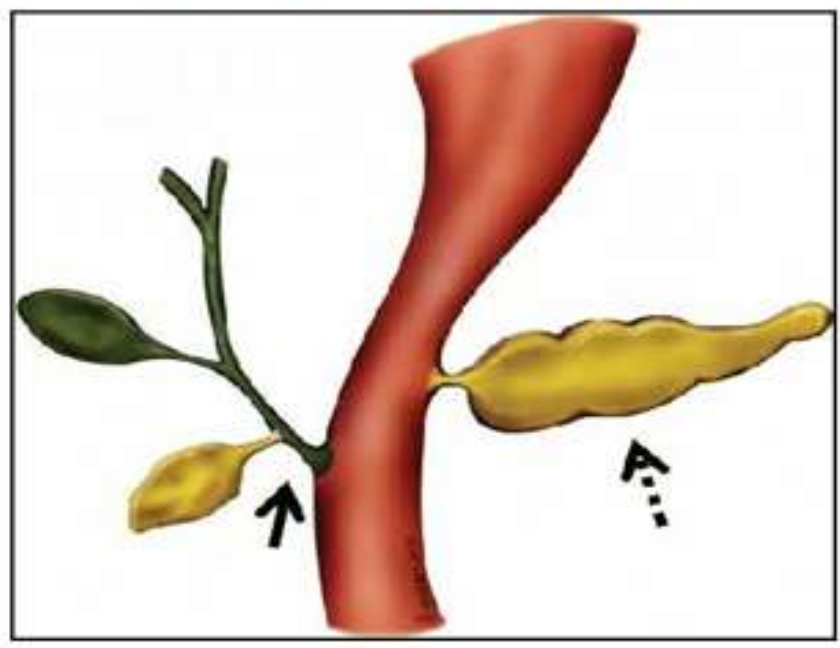

Figure 4: Final configuration of the pancreas after periduodenal rotation of the ventral bud and approximation of the ventral and dorsal pancreas. The dorsal pancreatic duct merges with the ventral (Wirsung) duct and rains into major papilla. The rudimentary distal dorsal duct (Santorini) drains into minor papilla.

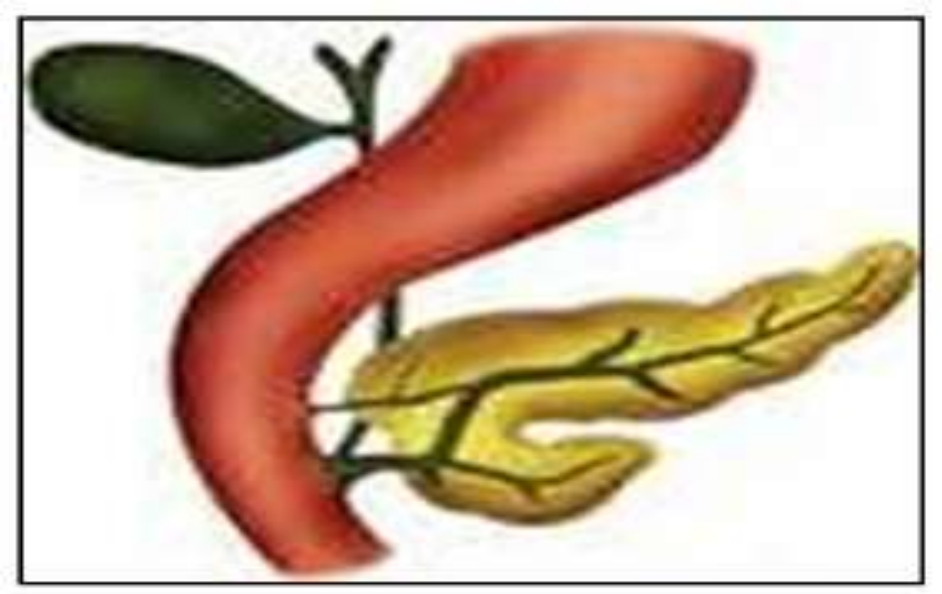

Figure 5: Annular pancreas. Ventral pancreas (arrowhead) encircles the second portion of the duodenum. The duct of the ventral pancreas (arrows) makes a turn around the duodenum and merges with the main dorsal duct in a normal fashion to form the Wirsung duct and drain to the major papilla.

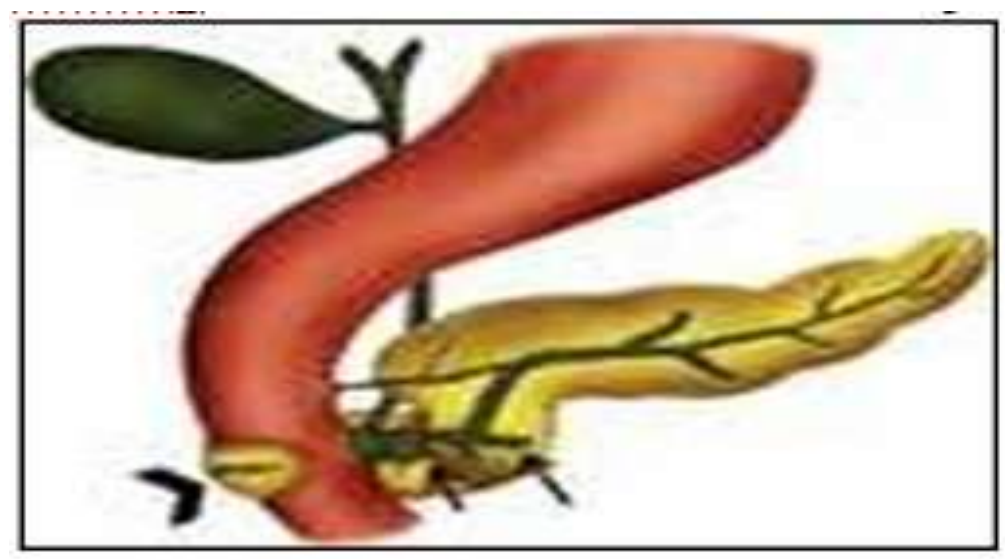


Figure 6: T2 Axial shows chronic pancreatitis with pseudocyst

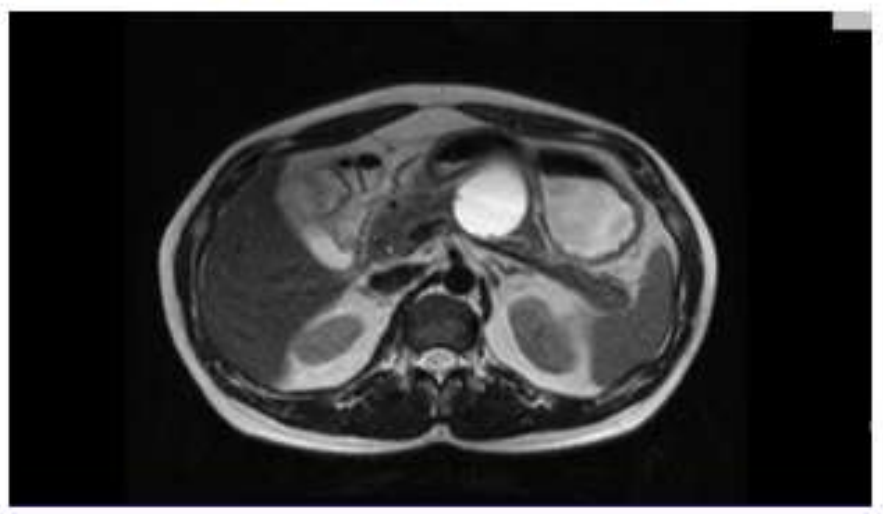

Figure 7 : T2 Coronal Shows Hypointense Calculus In Gall Bladder \& CBD

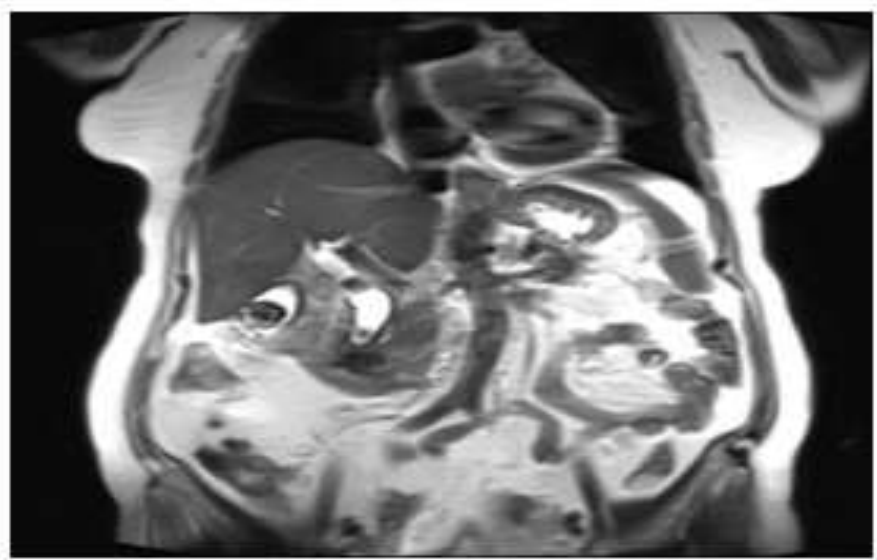

Figure 8: T2 AXIAL shows small Isointense mass lesion in the distal CBD. Distal CBD appears dilated and mild prominen ce of MPD noted -Suggestive of Periampullary Carcinoma.
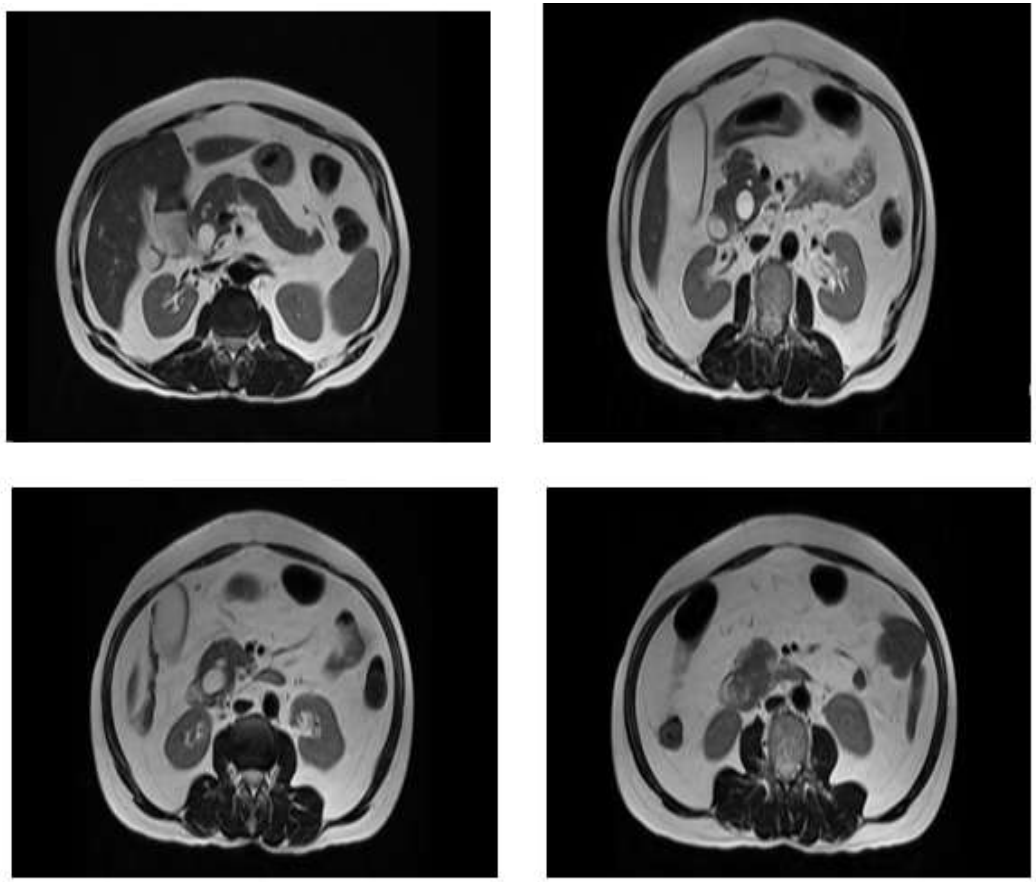
Figure 9: MRCP shows Dilated CBD and abrupt cutoff of distal CBD.

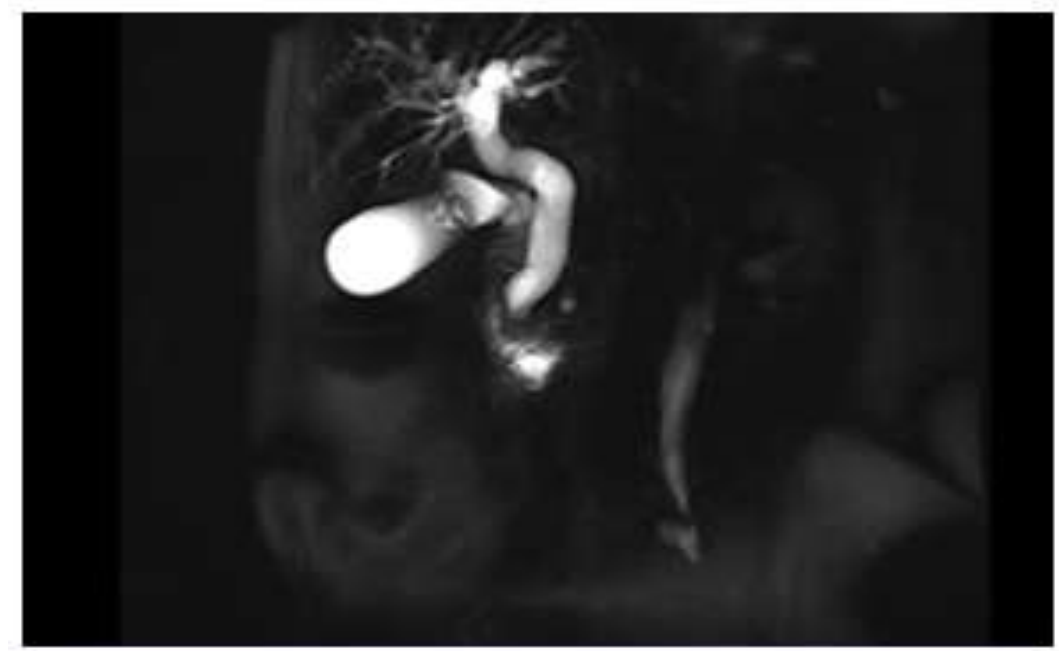

Figure 10 : ERCP images shows hilar stricture due to cholangiocarcinoma.

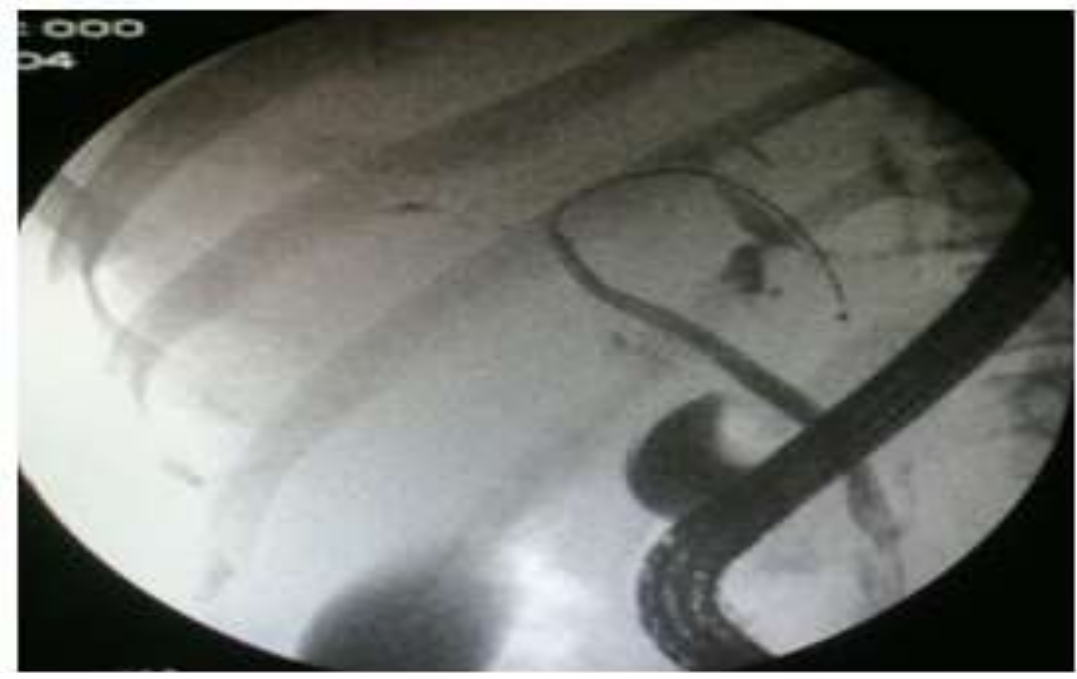

Figure 11: MRCP shows gall bladder calculi and dilated CBD. Irregular stricture with abrupt narrowing of distal CBD ( malignant stricture)

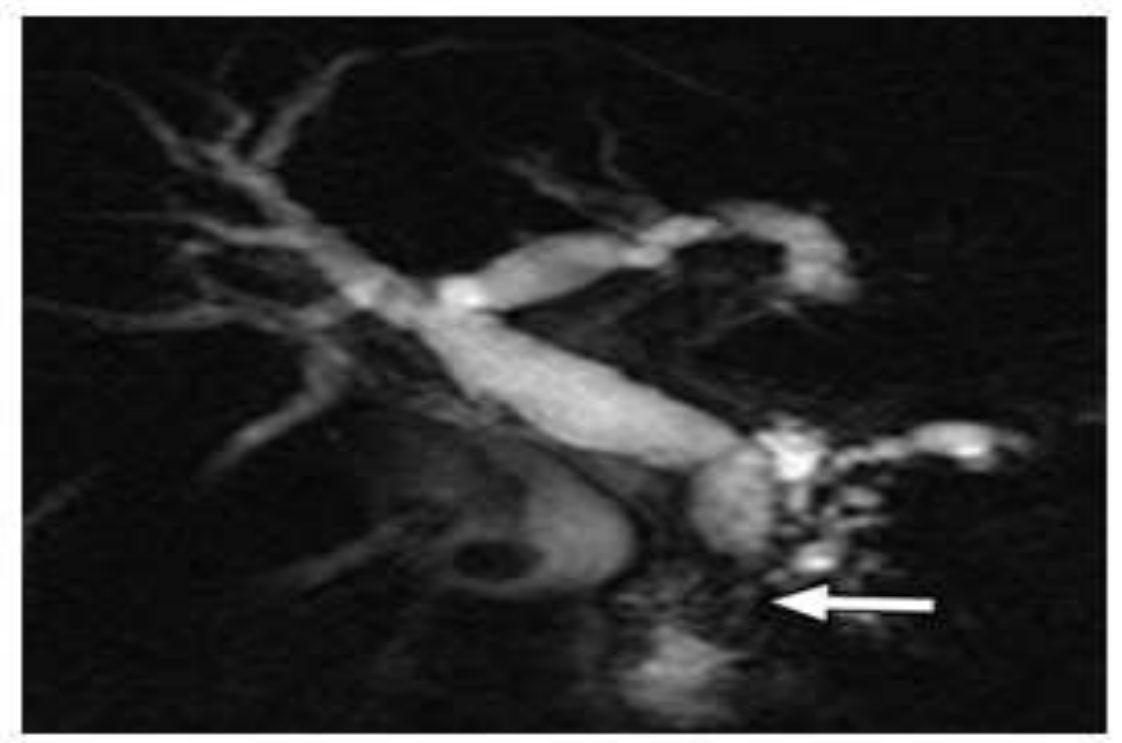


Figure 12 : T2 AXIAL Shows large hypointense calculus in distal CBD.

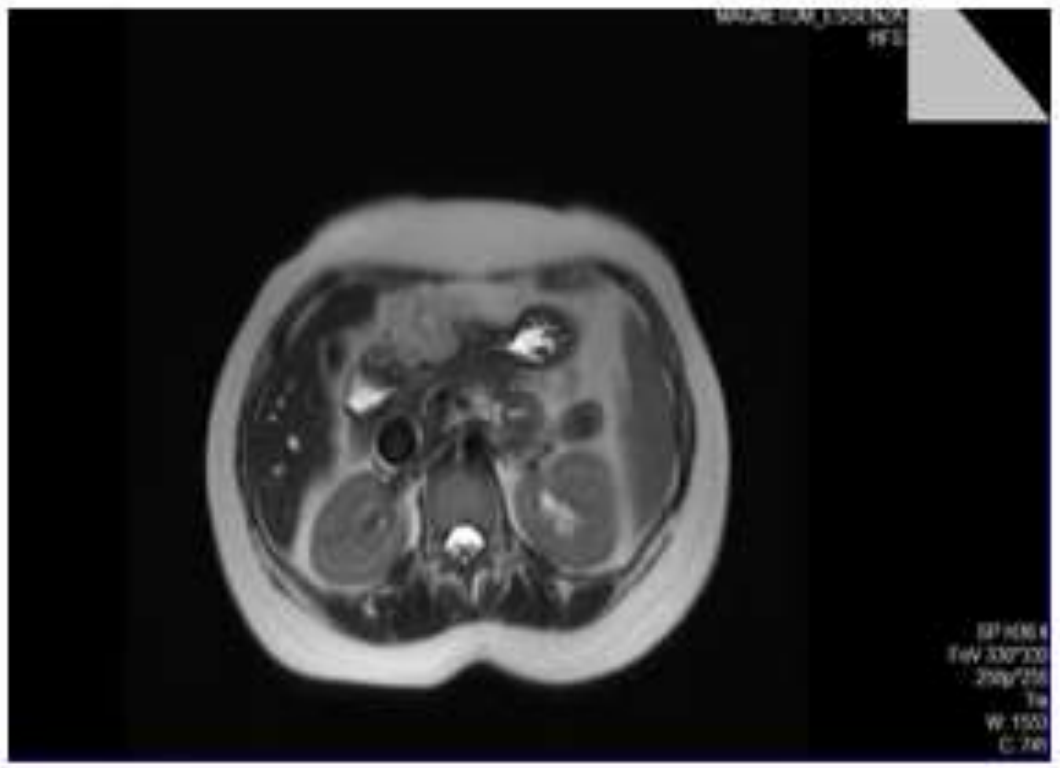

Figure 13: ERCP image shows calculus in distal CBD.

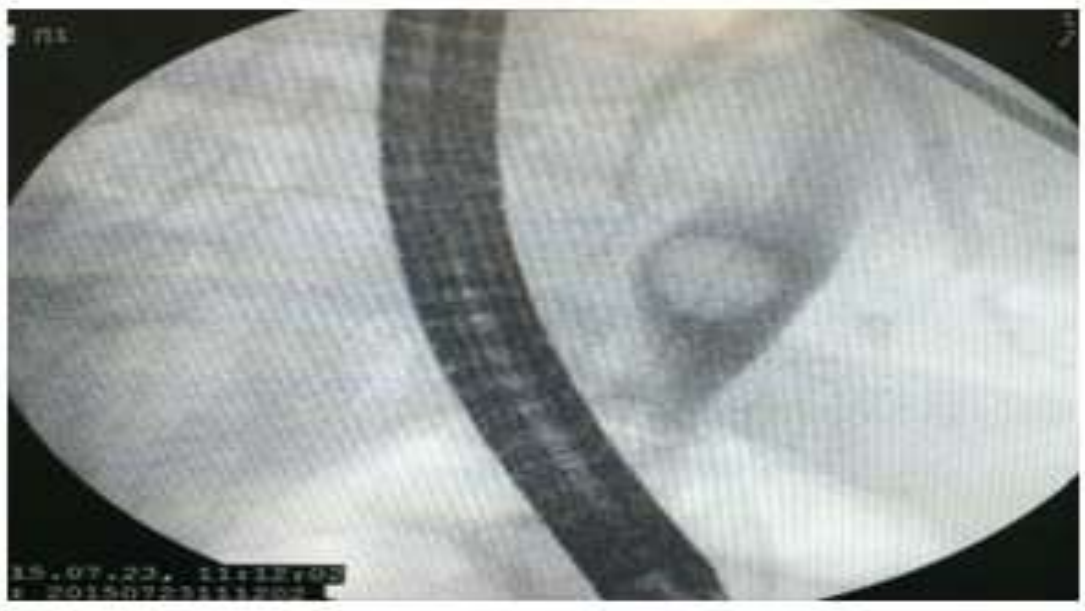

Figure 14 : T2 Haste shows large hypointense calculus in the distal CBD.

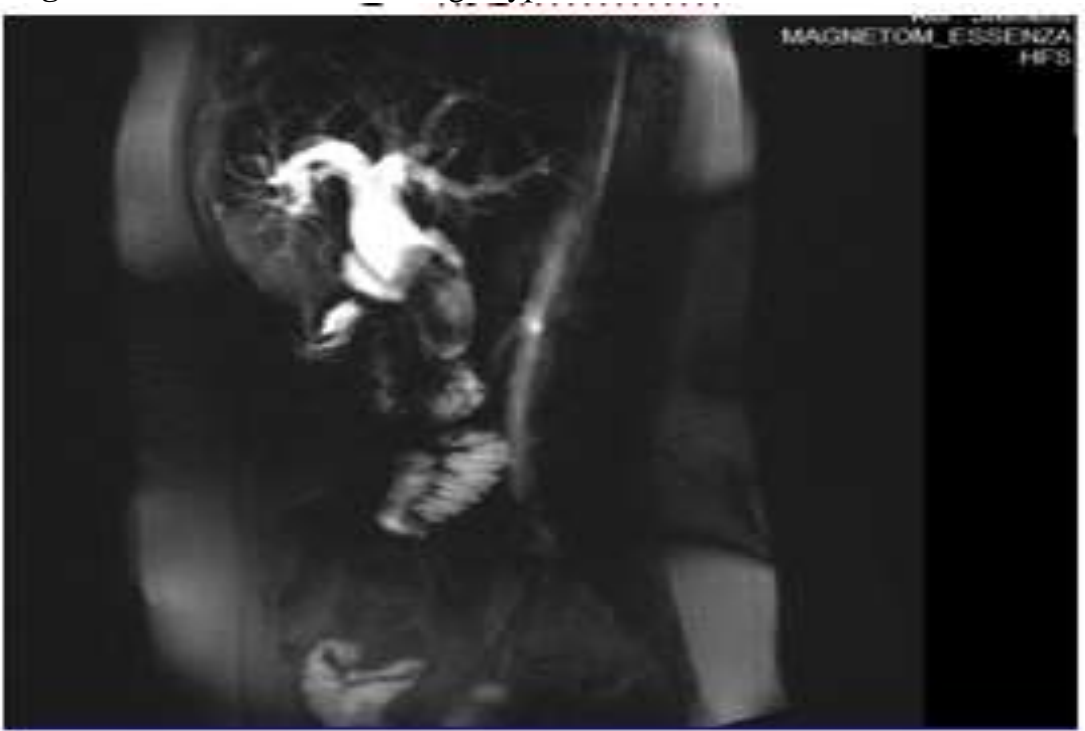


Figure 15 : T2 AXIAL CBD and MPD appears dilated with soft tissue mass lesion seen in mucosal aspect of the Periampullary region

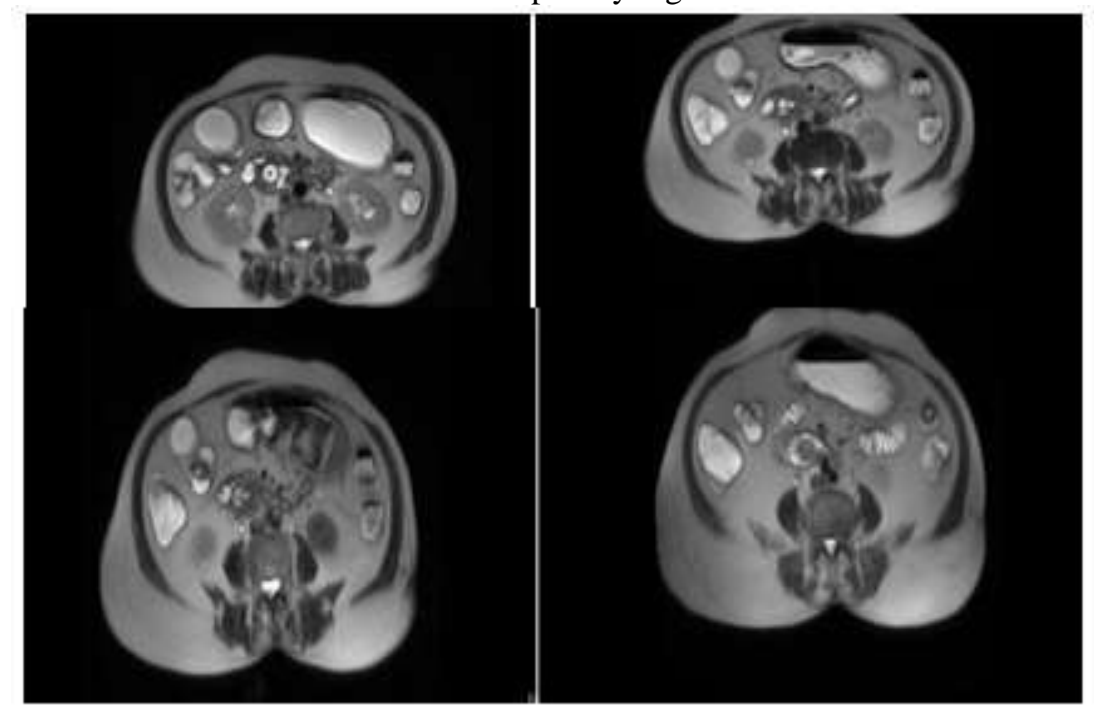

Figure 16: ERCP shows primary sclerosing cholangitis

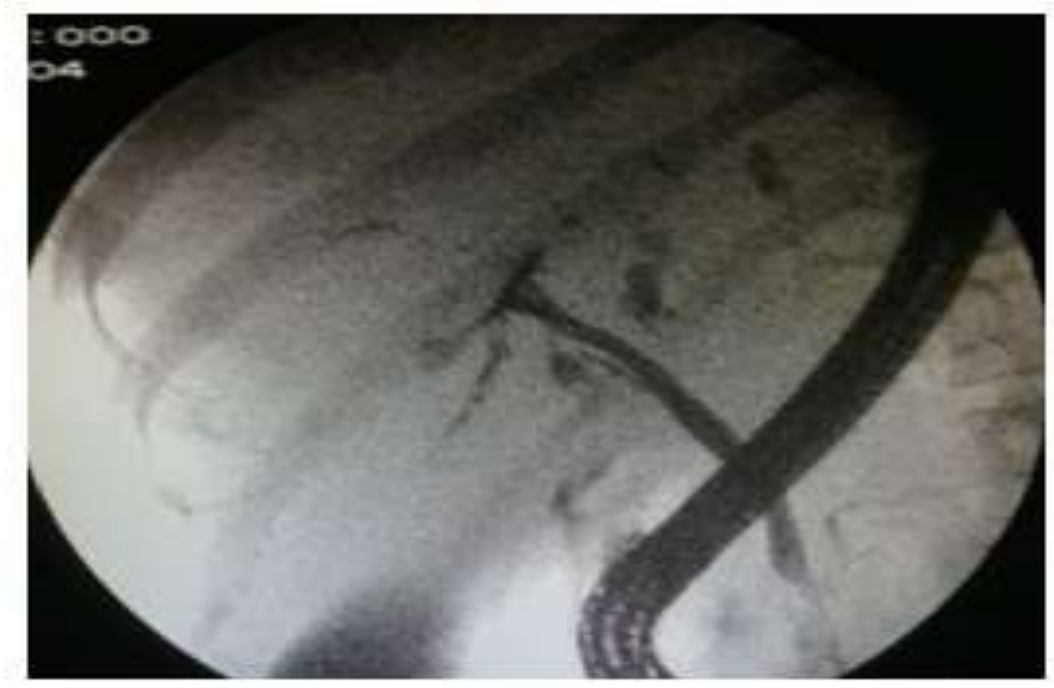

Figure 17: ERCP shows distal CBD narrowing (benign stricture, chronic pancreatitis)

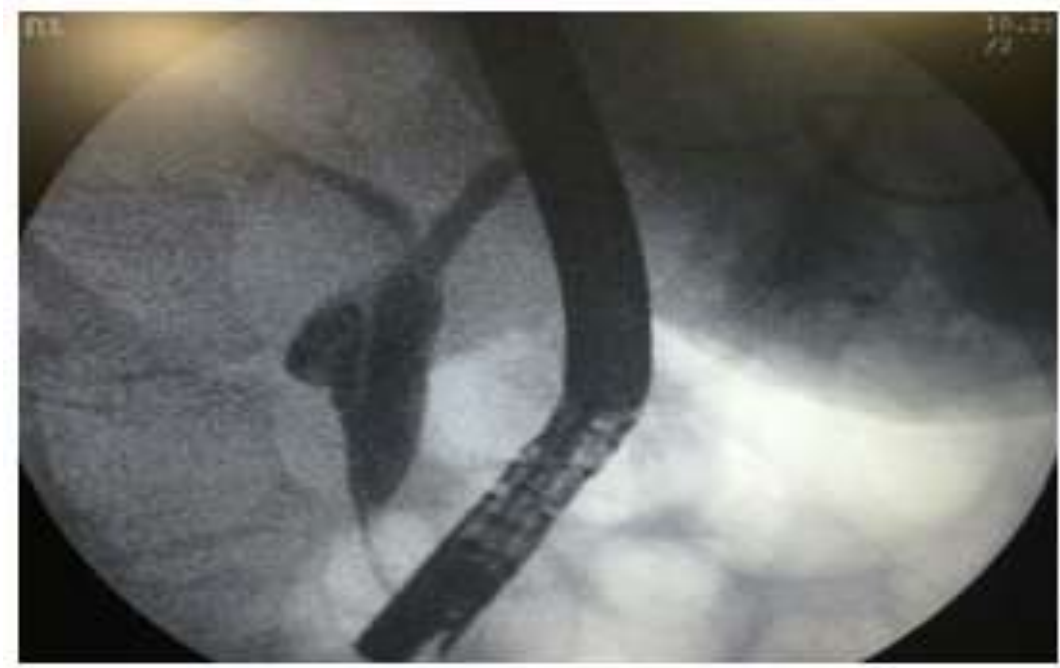

